\title{
ALGUNAS REFLEXIONES EN TORNO A
}

\section{LA RELACION: DERECHOS HUMANOS/}

DESARROLLO HUMANO

Gloria Clemencia Valencia G.

Fonoaudióloga. Máster en Desarrollo Educativo y Social. Especialización en Educación en Derechos Humanos. Docente Facultad de Fisioterapia. U. A. M.

\section{Anfora}

\section{INTRODUCCION}

n el actual contexto nacional e internacional es frecuente y casi permanente la alusión al tema de los Derechos Humanos, a la necesidad de pensar el hombre y la mujer en la compleja red de relaciones que se presentan en la actual crisis nacional y mundial.

La intención o intenciones que pueden existir detrás de esas alusiones son diversas y no siempre claras, sin embargo, lo que sí es claro es que los Derechos Humanos y la situación misma del hombre y la mujer en la sociedad, no son sólo un problema de imagen internacional. sino un punto crucial y decisivo para el devenir histórico de la humanidad, en un siglo de extremos: los más importantes y vertiginosos avances científico tecnológicos y al mismo tiempo uno de los más sangrientos períodos en la memoria de la humanidad.

Experiencias como la violencia, el miedo y la dominación 
irracional de unos a otros, coexisten tanto en reconocidos escenarios de guerra o de conflicto interno (Bosnia-Servia/Colombia), como en la cotidianidad de las relaciones sociales, comunales, vecinales, laborales, afectivas, en general en casi todos los espacios.

Así, la pregunta misma por el sentido y el horizonte de la humanidad, sus derechos, los retos de las nuevas formas y órdenes de relación, se presenta como uno de los ejes fundamentales de la discusión académica y social de hoy.

En este espacio no pretendo un exhaustivo análisis conceptual sobre el desarrollo humano y los derechos humanos, sino compartir algunas reflexiones logradas durante un tiempo de análisis sobre estas áreas.

Inicialmente presento algunas conceptualizaciones que identifican cada uno de los campos a relacionar y en un segundo momento, las categorías comunes que he ido encontrando como susceptibles de profundizar e investigar.

Precisiones básicas sobre el desa- rrollo humano y los derechos humanos:

Una mirada global a literatura sobre desarrollo humano, indica que su concepto varía no sólo de acuerdo con las corrientes teóricas sino con los mismos cambios históricos.

Se evidencia para el desarrollo humano una tensión macro/micro, es indudablemente un problema de colectividades, de grupos humanos con necesidades entendidas como potencialidad o como carencia- aspiraciones, intereses, pero es al mismo tiempo un asunto de individualidades, de sujetos que como tales, tienden a preservar y edificar su individualidad pero no en diálogo solitario, sino en proyección y relación con otros.

Un concepto de Desarrollo Humano es aquel que lo plantea como «el proceso de construcción de los sujetos individuales y colectivos, dentro de unas condiciones históricas y culturales específicas. La construcción de sujeto es el proceso central del Desarrollo Humano. Ser sujeto significa tener concien- 


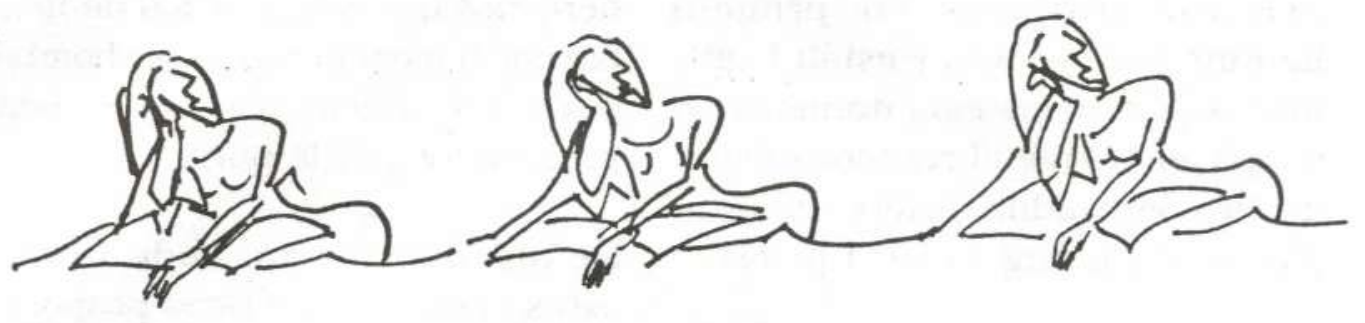

cia de sí, de sus acciones, sus características y circunstancias» (Sandoval, Carlos. 1995 p. 11).

El sujeto no es simplemente un ente, sino un ser que es histórico, social y cultural, no es simplemente, no puede decirse que es como un objeto o un mueble, como «una cosan, es un ser con historia en dos sentidos, por un lado su existencia tiene significado para él pero al mismo tiempo tiene significado para otros y resignifica la de otros.

A manera de propuesta podría senalarse que parte de la crisis actual se debe a que los procesos de desarrollo han estado muy centrados en la posibilidad de tener, desconociendo o menospreciando en alguna medida la capacidad de construir identidad, particularidad; lo cual permite entre otras cosas la reproducción de uno solo de los submundos, el material, que no es por si mismo garante de reproducción crítica del mundo de la vida, requiere la reproducción y actuación simbólica en el espacio de lo social.

Al remitirnos al concepto de Derechos Humanos encontramos que estos han estado presentes a lo largo de la historia de la humanidad, no necesiariamente como los conocemos hoy, ya que la declaración de los derechos del hombre de la Revolución Francesa data del siglo XVIII y la declaración universal de mediados del presente.

Sin embargo lo que si está claro es que siempre se ha tenido alguna idea del ejercicio de derechos de «una pugna entre el individuo y el poder... donde estos han surgido para limitar el papel de este último... Los Derechos Humanos no son creados sino descubiertos.» (Lozano 1994).

En lo que el propio Papacchini llama un intento de conceptualización, propone los Derechos Humanos como "reivindicaciones de unos bienes primarios considerados de vital importancia para todo ser humano, que concretan en cada época histórica las demandas de libertad 
y de dignidad. Estas reivindicaciones van dirigidas en primera instancia al Estado, y están legitimadas por un sistema normativo o simplemente por el reconocimiento de la comunidad internacional». (Pappachini, Angelo 1994 p. 22).

El papel de la historia aquí es el de dinamizador, de generador de situaciones, posibilidades, conflictos que promueven el descubrimiento de esa reivindicaciones y su puesta en marcha. No en una aséptica e ideal generalización sino en las condiciones y situaciones concretas de los grupos culturales humanos, con sus necesidades particulares, sus deseos y sus propias posibilidades de realización.

\section{Las concepciones teó-}

6 A manera de propuesta podría señalarse que parte de la crisis actual se de be a que los procesos de desarrollo han estado muy centrados en la posibilidad de tener ricas sobre los Derechos Humanos son variadas y orientan diversas acciones para su promoción y defensa, a manera de información se presentan elementos de las tres perspectivas que orientan la discusión actual:

El iusnaturalismo, los derechos como connaturales al hombre; el positivismo, los derechos como reconocimiento expreso de leyes y
Si compartimos con Papacchini su prupuesta de dignidad de la persona como una conquista del ser humano, como una construcción del sujeto, puede pensarse entonces la necesidad y posibilidad de pensar ese sujeto consciente y responsable de sí al que se aludió anteriormen-

te.

A título de introducción y como base para reflexiones posteriores, voy a referir ahora algunas categorías de análisis que hasta ahora he encontrado comunes entre el desarrollo humano y los derechos humanos:

\section{Relaciones Desarrollo Humano/ Derechos Humanos}


Estas categorías de relación, pueden pensarse en dos sentidos: uno referido a escenarios o si se quiere conceptos envolventes que sin agotar ninguno de los dos campos, proveen puntos de partida, de llegada, dificultades y posibilidades importantes y necesarias, son ellos: la comunicación y la cultura.

La comunicación como facilitadora de la promoción de los Derechos Humanos, mediadora su comprensión, interiorización $\mathrm{y}$ resignificación, en la cotidianidad de las personas y en las relaciones estado-ciudadanos, permite generar procesos educativos de diversa índole centrados en la vivencia de tales derehos, donde el ámbito educativo se convierte en foro de discusión, de intercambio cultural, de encuentro con el otro por ser diferente, con todos los retos y dificultades que la diferencia propone.

Igualmente, es mediante la práctica comunicativa que se crea una condición para establecer la defensa de los derechos humanos, donde se argumenten, se negocien las al- ternativas, se medien los conflictos. Una negociación de paz por ejemplo entre estado y un determinado grupo poblacional será tanto más eficaz, eficiente y efectiva, cuanto más claras se expresen las intenciones, se fundamenten las propuestas y tengan las partes visión cierta de las condiciones de validez y normatividad que regirán el proceso.

En este sentido es posible atreverse a pensar propuestas como la de Angelo Papacchini de encontrar en la declaración universal de los Derechos Humanos un horizonte ético para la humanidad (Papacchini 1994), a partir no de la uniformidad de los mismos en todas las latitudes del mundo, sino de la interpretación cultural particular, que permita a cada grupo humano, construir los sentidos y significados propios alrededor de los derechos allí plasmados.

¿Relativizar algunos derechos?. NO, encontrar y optar por esos mínimos necesarios para la convivencia de la humanidad, con posiciones explí-

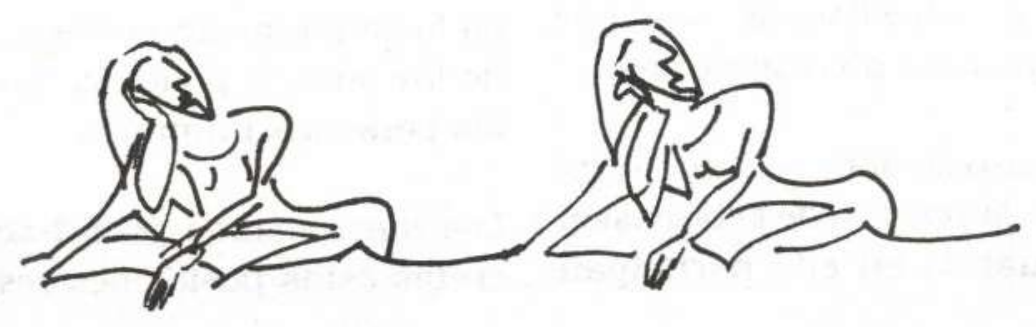

Universidad Autónoma 
- Una negociación de paz por ejemplo entre estado y un determinado grupo poblacional será tanto más eficaz, eficiente y efectiva, cuanto más claras se expresen las intenciones ${ }^{9}$

citas y definidas de acuerdo con la dignidad de las personas y con las necesidades propias de los textos culturales.

Es mediante argumentaciones que los sujetos logran develar sus propias contradicciones, en búsqueda permanente de planteamientos cada vez más válidos en cada situación específica, de tal manera que puedan generarse los consensos necesarios.

Cabe señalar aquí a qué hago referencia con el término consenso, empezando por aquello que no es, puede decirse que en ningún momento se trata de estar todos de acuerdo en todo, ni que al primer planteamiento todos los participantes ascientan como señal de acuerdo; por el contrario, se refiere a la posibilidad de lograr los acuerdos a partir de las divergencias y dentro de ellas, de escuchar a las mayorías y a las minorías.

«El consenso se obtiene... como resultado de la práctica de la discusión moral, cuando en ella participan libremente los afectados por el conflicto en cuestión, tiende a ser indicativo de la imparcialidad, y por tanto de la corrección moral de la solución adoptada, ya que la unanimidad es equivalente funcional, bajo ciertas condiciones de imparcialidad» (Nino 1995 p. 14).

La cultura partiendo del concepto de Geertz, según el cual la cultura es «documento activo, es... pública... no existe en la cabeza de alguien aunque no es física, no es entidad oculta... es un texto borroso para ser leído» (Geertz 1988 p. 19-40).

En ese texto, en ese documento patrimonio de todos, sin ser propiedad de ninguno, se encuentran las violaciones, las alternativas, las necesidades y las vías para la defensa y promoción de los Derechos Humanos, en los microespacios diarios de la vida social y personal y en la conformación y consolidación de los sujetos políticos que somos las personas humanas.

Los mecanismos para hacer concretas estas posiciones respecto a 
lo comunicativo y lo cultural, pueden no estar definidos pero al menos se presentan estas dimensiones como puntos de referencia desde los cuales analizar y concretar acciones.

En lo específico de los campos derechos humanos/desarrollo humano. aparecen las categorías individual y social, moral-valorativo y político. como puntos de intersección, espacios donde se encuentran estos dos campos conceptuales y cuyo desarrollo puede ser vital para la convivencia futura de la humanidad.

Como intento de finalización puede decirse que la promoción y defensa de los derechos humanos, se convierte en reto en la medida que a partir del desarrollo libre, crítico, autorresponsable holístico, desde lo simbólico, lo social y lo material, puede pensarse la vivencia de los derechos humanos como una práctica cotidiana, que requiera cada

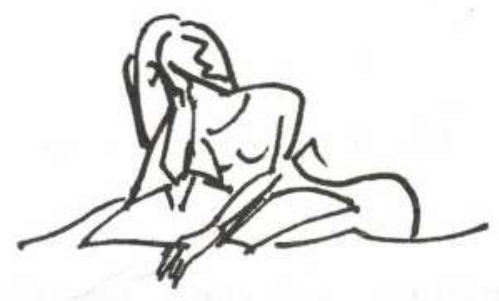

vez menos intervención coersitiva y mayor acción autónoma individual y colectiva.

Son alternativas para el desarrollo humano por cuanto desde ellos, puede encontrarse un horizonte de sentido, de acción que guíe y oriente un nuevo orden social, no «universal ni unilateral» sino pensado a partir de la interpretación cultural de los mismos en los diferentes procesos históricos.

\section{BIBLIOGRAFIA}

GEERTZ. Guilford. Descripción Densa. Hacia una teoría interpretativa de la cultura. En: Aporte. Cultura Enfoques Recientes. Dimensión Educativa. Santafé de Bogotá. 1993.

PAPACCHINI. Angelo. Un Sistema de valores para nuestra situación y para nuestro tiempo. En: Valores para una ética ciudadana. 1992.

REY, Germán. Algunos temas generales en las teorías psicológicas del desarrollo humano. Bogotá: Universidad Javeriana, Fácultad de Estudios Interdisciplinarios, 1990.

SANDOVAL y otros. Lenguaje, Comunicación y Desarrollo Humano. Medellín, 1994. 